\title{
Reseña del libro de Eduardo Míguez, Crítica (y reivindicación) de la universidad pública ${ }^{1}$
}

Jaime-Arturo Aragón-Falomir

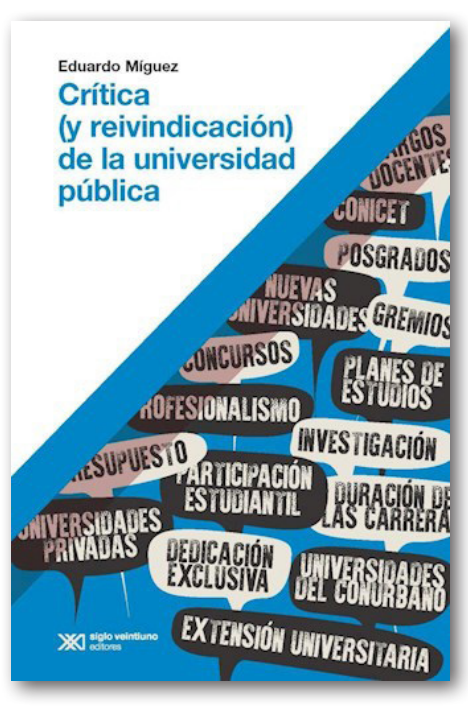

A sistimos, en el debate contemporáneo que engloba las ciencias sociales y humanas, a un loable interés por incorporar las desigualdades como eje central, lo abordan tanto trabajos de investigación individuales o grupales, como organizaciones internacionales, fundaciones y otras entidades. El sector educativo no es, por lo tanto, ajeno a dicha coyuntura analítica. La obra del historiador argentino Eduardo Míguez, se adhiere a esa necesidad imperiosa por comprender la naturaleza de esta coyuntura y los múltiples desafíos que presenta el sector educativo en tanto en cuanto cumpla su rol como "agente de cambio y crecimiento" (p. 23). Para Míguez la educación debe, por consiguiente, impactar tanto en indicadores puramente educativos (deserción, financiamiento, autonomía, precarización laboral del personal educativo, manejo de recursos, etcétera) como en desigualdades sociales (pobreza o indigencia, mortalidad infantil, esperanza de vida, etcétera).

\section{Jaime-Arturo Aragón-Falomir}

jaime.aragonf@gmail.com Mexicano. Doctor y magister en Ciencias Sociales por la Universidad Sorbona de Paris, Francia. En el marco de una beca posdoctoral para latinoamericanos del CONICET, realiza una estancia de investigación y seminarios de posgrado en la Universidad Nacional de Rosario (UNR) para completar su formación académica. Es actualmente catedrático-investigador temporal (ATER) en la Universidad de las Antillas, polo Martinica. Al mismo tiempo, co-dirige al área regional Argentina en el proyecto comparativo de ocho países sobre Educación Superior Privada y Desigualdades (ESPI, por sus siglas en francés) dirigido por Etienne Gerard (Instituto de Investigación por el Desarrollo, IRD por sus siglas en francés). Temas de Investigación: educación, desigualdades, elites políticas y empresariales.

\footnotetext{
${ }^{1}$ Eduardo Míguez (2018), Crítica (y reivindicación) de la universidad pública, Buenos Aires, Siglo XXI.
} 
Empero, el otrora vanagloriado sistema educativo argentino, según Míguez, dejó de ser aquel agente de cambio. Es ahí donde yace el objetivo central del libro, plantear un diagnóstico sobre las dificultades que enfrenta la universidad argentina: tanto causas como soluciones. Aunque más que un programa preciso, el historiador busca con una escritura lacónica "mostrar la necesidad de hacerlo" (p. 168). Sobre el sistema educativo argentino, comenta que vive una suerte de retroceso frente a sus pares de la región "más por el fracaso argentino que por el éxito de sus vecinos" (p. 10). Lo cual perjudica a los más necesitados pues los deja "en términos relativos - y, en cierta forma, también en absolutos - cada vez peor" (p. 10). Exacerbando, como consecuencia, las desigualdades.

En efecto, el sugestivo título muestra que la crítica tendrá un lugar central que marca el agudo pulso de la obra y que, si bien la "reivindicación" está presente, estará acotada. El texto se convierte en un documento esencial para entender las aristas problematizadas que podemos encontrar en su análisis del caso argentino, igualmente reflejadas en sistemas educativos latinoamericanos. La experiencia de Míguez como actor dentro del sistema educativo tanto en su periodo formativo - hijo del rector del Instituto de Estudios Teológicos, militante estudiantil en la Facultad de Filosofía y Letras de la Universidad de Buenos Aires (UBA) y doctor por Oxford-, como en el profesional - decano, vicerrector, profesor titular, evaluador de la Comisión Nacional de Evaluación Universitaria (CONEAU), entre otros-, le permite tener una experiencia amplia y variada acerca de su biotopo: la educación y la universidad.

Con una introducción que deja sin aliento, el autor deconstruye y asevera que, si bien Argentina es un país no desarrollado, sería más pertinente decir que está "en vías de subdesarrollo" (p. 9), es decir involucionando. Define el subdesarrollo como "la incapacidad para generar las condiciones que permitan satisfacer las necesidades [...] para llevar una vida acorde a las expectativas individuales y colectivas" (p. 10). En concreto, su hipótesis principal es que el problema de estos países no es la falta de recursos "sino su mal uso [...] uso inadecuado" de éstos (p. 11). Pero ¿qué correlación tiene esto con el sistema educativo? Si bien no es culpable, argumenta, "tampoco contribuye, tal como está, a revertirla" (p. 10). Esto es debido a dos razones principales: en su seno experimenta la mala utilización de recursos y sus miembros, quienes deberían contribuir a superar ese problema, son parte de dicho mal uso.

Míguez abre trincheras en múltiples frentes. Menciona que es imposible tener una buena educación sin profesores de calidad con perfiles bicéfalos entre la docencia e la investigación (bien remunerados y con estabilidad laboral). De hecho, recomienda expandir la planta de catedráticos full time y disminuir la proporción del gasto en personal administrativo. Otro de sus argumentos es un llamado al "sinceramiento de los sistemas estadísticos [...] que siguen distorsionando la imagen de nuestro propio sistema" (p. 160). De esta forma, las cifras cuantitativas oficiales (de estudiantes, nuevos ingresos y graduados) deben servir para entender no cuántos, sino quiénes (y por qué) obtienen el diploma y quiénes (y por qué) desertan.

De igual forma, en este sinceramiento, se debería abordar el financiamiento, otro de sus más sólidos postulados. Al desglosar las cifras de inversión estatal, muestra que la inversión promedio por estudiante en la Argentina es de 3100 dólares anuales (según el presupuesto del 2016). Esto lo lleva a decir que: 1) las asimetrías son visibles, ya que la atribución no es proporcional: mientras que en la Universidad de la Matanza (zona conurbana de Buenos Aires) no llegaba a los $\$ 1700$, en la de la provincia de San Juan (al oeste, colindante con Chile) llega a casi $\$ 6500$ - sin justificación por número de estudiantes o calidad científica. 2) Al observar el caso brasileño, con una inversión superior por estudiante a la argentina, moviliza el ejemplo de la Universidad de San Pablo, que asume un gasto de 26000 dólares por alumno (en 2014). 
Esta cifra haría pensar que Brasil hace un uso verdaderamente malo de los recursos. No obstante, y es aquí donde toma forma su argumento, Míguez propone considerar el costo por graduado (y no por estudiante inscrito), para compararlo con la tasa de graduación: en la USP dicha tasa es del $75 \%$ es decir un costo de 35000 por graduado y en Argentina, donde es de menos de $10 \%$, la inversión implica un costo real de 57000 por alumno con diploma (pp. 21-22).

Con argumentos como éstos, el autor plasma con una narrativa simple, profunda, explícita y lapidaria, con analogías y comparaciones tanto con países de la región (Brasil, Uruguay o Chile) como con Europa (el Plan Bolonia o la desarticulación de la Sorbona de París), un trabajo que en las escuetas 168 páginas se convertirá sin duda en referente en los trabajos sobre la educación. Esto gracias a su perspectiva crítica y reivindicatoria sobre el rol que deberían cumplir los sistemas educativos como "agentes de cambio" - y no, únicamente, como impresores de diplomas. El documento está dividido en una introducción y siete capítulos con un equilibrio de alrededor de 20 páginas cada uno (con la excepción de los dos últimos, más cortos).

En el primer capítulo, el autor busca entender la conducción de la universidad, trabajando temáticas como los limites de la autonomía, la duración de carreras, la política sobre la oferta académica, el manejo discrecional de recursos, entre otros. Sostiene por ejemplo que la sobrerrepresentación estudiantil en consejos universitarios es innecesaria (a su juicio, debido a la limitada experiencia de éstos en la gestión educativa). Así pues, propone que formular un buen diagnóstico llevaría a "implementar las decisiones que deberían afectar al conjunto de las instituciones universitarias" (p. 30), esto no avasallaría la libertad, sino que, en opinión del historiador "racionaliza y optimiza el uso de recursos públicos" (p. 31). Menciona que la intromisión de la vida partidaria en la universidad afecta a su buena gestión, con partidos políticos que "controlan" tácitamente ciertas instituciones.
"Buenas intenciones, malos resultados" es el título del segundo capítulo, donde Míguez evoca las políticas universitarias, los mecanismos de financiamiento, la inserción laboral, los intercambios internacionales de docentes o estudiantes y la deserción. Hace hincapié en repetidas ocasiones en que buenos investigadores al ser catedráticos mejoran la capacidad de construir pensamiento crítico y analítico de sus estudiantes (p. 52). Articula un debate acerca de dos temas álgidos: la gratuidad y el ingreso irrestricto. El primero lo considera como "una redistribución inversa de la riqueza" (p. 55), es decir "a favor de sectores medios y altos" (pp. 57-58). En cuanto al segundo, concibe importante revisarlo, puesto que "es una ficción que en la práctica encubre un sistema de selección costoso y cruel. Es un sistema costoso porque el proceso selectivo es largo e involucra muchos recursos humanos y físicos que se utilizan de manera poco eficiente. Es cruel, porque expone a las personas a ingresar a la vida universitaria sólo para sufrir la frustración de no poder avanzar en ella" (p. 63).

En la tercera parte el historiador describe los programas académicos. En éste hace un elogio al Plan Bolonia, al menos en la resolución de conflicto que homogeneizó la duración del diploma de grado (licenciatura) en los países miembros de la Unión Europea. En esa línea, denuncia que Argentina tiene una sobre duración excesiva oficial de cinco años, la cual rara vez es respetada pues se prolonga a siete o incluso a nueve años. Míguez propone que debería tenerse en cuenta la oferta y la demanda, así como el grado de inserción laboral que conlleva cada formación. Por un lado, ya que "el Estado sostiene ofertas que satisfacen más que nada la necesidad de inserción laboral de los docentes" (p. 83) y por otro, puesto que "la mayoría termina en un trabajo en el que hace más uso de la formación general recibida que de los saberes específicos o del título” (p. 84).

En el cuarto apartado el tema es la docencia. En este punto es tajante, puesto que afirma que sin las condiciones económicas los profesores no pueden 
ejercer su labor de manera óptima (y por lo tanto ser agentes de cambio). Esto a pesar de que "el sistema ha definido como deseable que la mayoría de sus docentes se dediquen a la labor universitaria a tiempo completo" (p. 100). Analiza también, la relación del número de alumnos por profesor, en Argentina se sitúa alrededor de un docente por 27 estudiantes, y en la USP de Brasil, 16 pupilos en promedio. Estudia igualmente la relación de los docentes o investigadores con el Consejo Nacional de Investigaciones Científicas y Técnicas (CONICET) y con sus universidades, donde uno es quien financia y el otro es donde ejerce su labor de docente, un limbo institucional de pertenencia.

El quinto capítulo aborda el vínculo entre docencia e investigación. Pone énfasis en la importancia que debería atribuírsele a la investigación, pero por otro lado menciona los recovecos de las contrataciones en función de papers con referato - muchas veces imposibles de obtener-, lo cual descarta cruelmente a candidatos óptimos para el puesto. También considera que la estructura de cátedra que tiene el sistema educativo argentino es anacrónica y disfuncional, conlleva que personas con las aptitudes de dar clases como titulares estén contratados como asistentes, con nivel y horarios de titular — sin los salarios, las prestaciones y el reconocimiento que merecen. Los salarios, sin ser despreciables, son por otro lado poco competitivos frente a los chilenos o brasileños, y ni que decir, los europeos o estadunidenses.

En la sexta sección estudia brevemente a las universidades privadas, las cuales considera "una vía de acceso a la educación superior más eficaz que la de gestión pública para sectores [paradójicamente] menos favorecidos" (p. 148). En este apartado menciona dos puntos trascendentales. Por una parte, la flexibilidad horaria en la universidad privada es mayor, lo cual beneficia a sectores más desfavorecidos que estudian y trabajan. Por otra parte, son más acogedoras y menos indiferentes hacia el alumno, dentro de otras razones por una cuestión de escala. Ahora bien, la exigencia académica es sin duda menor, escribe Míguez, ya que es raro encontrar profesores full time con el tiempo para ésta en la vanguardia pedagógica. A pesar de eso acepta que la universidad privada es una vía de acceso para los sectores más vulnerables, en general son la primera generación con estudios superiores (p. 148). Ahora bien, dentro del crisol de instituciones privadas (algunas de gran nivel) emerge otro dilema que las becas socioeconómicas son incapaces de remediar, la persistente exclusión social (p. 150). Es decir, el medio sociocultural de la mayoría de las familias, provenientes de sectores con altos ingresos y con un desarrollo cultural manifiesto puede ser profundamente hostil para aquellos más desfavorecidos.

Eduardo Míguez concluye su pensamiento proponiendo "pensar en una renovación más creativa de las estructuras de conducción, diferenciar roles e instancias, combinar criterios técnicos con la amplitud y diversidad de participación" (p. 38). Para esto, el papel protagónico como promotor le corresponde al gobierno central, sin avasallar la autonomía universitaria. Por eso cree que con "imaginación, ingenio y debate" se podrán resolver los problemas (p. 156). En aras de reducir las desigualdades a través de una redistribución auténtica con docentes de calidad, en puestos de investigación, y estudiantes con un porvenir con ascensión social real. Habrá que hacer una diferenciación, a su juicio, en función de las carreras, observando tanto la calidad de egresados como la garantía mínima de calidad con que deben incorporarse al mercado laboral. Aunque debate álgido, propone debatir el arancelamiento y otro tipo de becas (de subsistencia y no sólo de matrícula). Más allá de sus propuestas, el texto abre más inquietudes e hipótesis de cómo reducir la brecha entre las poblaciones más desfavorecidas que las que cierra, con múltiples propuestas por debatir. Una pregunta contemporánea válida sigue girando alrededor del ingreso irrestricto. Si bien el examen de admisión es un filtro con base en conocimientos y habilidades, lo 
cual está relacionado con el estatus socioeconómico del hogar: ¿aleatorizar es la mejor y más viable solución para romper este vínculo?

Los sistemas educativos mundiales están en una encrucijada frente al cúmulo de dilemas y problemas contemporáneos, si bien la obra de Eduardo Míguez se enmarca en una contribución científica sobre Argentina, muestra aspectos e interrogantes vigentes, verosímiles y constantes en otras latitudes acerca de una batalla a futuro pendiente que debería saldar la educación.

\section{Cómo citar este artículo:}

Aragón-Falomir, Jaime-Arturo (2020), "Reseña del libro de Eduardo Míguez, Crítica (y reivindicación) de la universidad pública”, Revista Iberoamericana de Educación Superior (RIES), vol. XI, núm. 32, pp. 229-233, DOI: https://doi.org/10.22201/iisue.20072872e.2020.32.824 [Consulta: fecha de última consulta]. 